Bangladesh Journal of Neuroscience 2016; Vol. 32 (1): 28-33

\title{
Association between Admission Hyperglycemia and Outcome in Actue Ischemic Stroke Cases: An Observational Study
}

\author{
DAS P C ${ }^{1}$, ISLAM M M ${ }^{2}$, SARKAR $\mathrm{S}^{3},{\text { KUNDU N }{ }^{4} \text {, RAHMAN T }}^{5}$
}

\begin{abstract}
:
Background: A high proportion of patients suffering from an acute stressful condition asuch as stroke or myocardial infarction may develop hyperglycemia even in the absence of a preexisting diagnosis of diabetes. The study evaluates the effect of hyperglycemia in the severity and outcome during the acute phase of stroke. Methods: This was a descriptive cross-sectional study. Baseline variables (eg: age, sex, smoking, hypertension, diabetes OHA/insulin) and outcome measures (mortaily, disability) were statistically analysed and compared with a control group of 50 patients of acute ischemic storke without admission hyperglycemia. Result: the base line characteristis of the two patient groups were comparable. The $1^{\text {st }}$ week mortality was $16 \%$ in case group and $2 \%$ in the control group. the 30 days mortality in the case group and control group was $28 \%$ and $12 \%$ respectively, $58.33 \%$ were disabled \& dependent in the hyperglycemia group, in comparison to $36.36 \%$ subjects in the control group. Conclusion: Admission hyperglycemia seems worsen the outcome and functional disability during the acute phase of Ischemic stroke. Admission glucose level is an important risk factor and should be immediately treated to reduce morbitidity \& mortality in acute Ischemic stroke cases
\end{abstract}

Key words: Stroke, Hyperglycemia, Cerebral Ischemia, cerebro vascular Injury disability.

Introduction:

Stroke is one of the leading causes of death and disability world wide and more so in underdeveloped countries like Bangladesh where health support system including rehabilitation is not expectedly available. At least $50 \%$ of the neurological disorder in a general hospital is stroke. World Health Organizasion (WHO) defined Stroke as rapidly developiong clinical signs of focal or global disturbance of cerebral function, with symptoms lasting 24 hours or longer or leading to death, with no apparent cause other than vascular origin ${ }^{1}$. Most of the stroke is due to cerebral infarction ((80\%) the rest is due to haemorrhage. Modifiable risk factors for stroke include hypertension, diabetes, atrial fibrillation, dislipidemia, smoking and alcohol abuse. About one third of patients with acute stroke and no prior diagnosis of diabetes have hyperglycemia during acute phase of stroke. Wether this is an acute stress response or a reflection of underlying diabeties is controversial ${ }^{2}$. Hyperglycemia has been reported to worsen the lolerance of the brain to ischemia ${ }^{3,4}$. The early recognition of disorder of glucose metabolism in stroke patients is important because hyperglycemia during the acute phase worsens the outcome probably by reducing the salvage of penumbral tissue medicated by high lactate level of brain tissue 5 . Despite these observations, the relationship between glucose level and outcome after stroke in diabetic and nondiabetic patients has not been well characterised and those studies that have examined this relationship have reported confliciting results ${ }^{6}$. The present study is carried out to find out the relationship of admission hyperglycemia and its

1. Dr. Priyatosh Chandra Das, Associate Professor, Department of Neurology, Shaheed Suhrawardy Medical College, Dhaka

2. Dr. Mohammad Mohitul Islam, Assistant Professor, Department of Neurology, Shaheed Suhrawardy Medical College, Dhaka

3. Dr. Saumitra Sarkar, Associate Professor, Department of Neurosurgery, Shaheed Suhrawardy Medical College, Dhaka

4. Dr. Narayan Chandra Kundu, Associate Professor, Department of Neurology, Shaheed Suhrawardy Medical College, Dhaka

5. Dr. Touhidur Rahman, Assistant Professor, Department of Neurology, Chittagong Medical College, Chittagong 
outcome in terms of mortality and morbidity after an acute ischemic stroke.

\section{Methods:}

This descriptive cross- sectional study was done among patients admitted in Shaheed Suhrawardy Medical College Hospital between July 2012 - June 2013. Tomographic (CT) diagnosis of ischemic stroke with admission hyperglycemia (RBS $>8 \mathrm{mmol} /$ $L)$ were included in the study. Patterns with intracerebral haemohage, subarachnoid haemorrhage transient Ischemic attack and with non-stroke cause of focal neurological deficit eg. brain tumour were excluded from the study. Those patients with associated co-morbidity like myocardial infraction, atrial fibrailation, cancer was not included in the study. 100 patients were selected by purposive type of nonprobability sampling technique. A random blood glucose was measured on admission (or within 24 hours of admission) to define admission hyperglycemia (RBS $>8 \mathrm{mmol} / \mathrm{L}$ ). Among them 50 patients who fulfilled the inclusion criteria were selected as case group and another 50 patients with RBS $<8 \mathrm{mmol} / \mathrm{L}$ were selected as control group. Data were collected by taking medical history,clinical evaluation and laboratory investigations in a structured data sheet.

The samples under study were examined for assessment and follow up during admission, one week after admission and after one month of discharge from the hospital. Outcome was assessed in terms of fatality and functional recovery after 30 days adjusting age, stroke severity and comorbid conditions parameters used for assessment of stroke severity and outcome were the NIHSS (National Institute of Health stroke scale) and the modified Rankin Scale (MRS) ${ }^{7}$. Data were analyzed by statistical package for social science (SPSS) programme.

\section{Result:}

The mean age of the control was $60.10+11.35$ years and that of cases was $60.80(+12.37)$ years. Majority of the patients belonged to the $6^{\text {th }} \& 7^{\text {th }}$ decade of life. Analysis found no statistically significant difference between the mean age of the control and the cases $(P>0.05)$. This is shown in Table I

\section{Tabel-I}

Age distribution of study subjects ( $n=100$, control 50, case 50)

\begin{tabular}{lccc}
\hline Age group & \multicolumn{2}{c}{ Study Subjects } & p value \\
\cline { 2 - 3 } & $\begin{array}{c}\text { Case } \\
\text { No. }(\%)\end{array}$ & $\begin{array}{c}\text { Control } \\
\text { No. }(\%)\end{array}$ & \\
\hline $21-30$ & $1(2)$ & $2(4)$ & \\
$31-40$ & $2(4)$ & $0(0)$ & 0.769 \\
$41-50$ & $9(18)$ & $6(12)$ & \\
$51-60$ & $11(22)$ & $21(42)$ & \\
$61-70$ & $19(38)$ & $14(28)$ & \\
$71-80$ & $7(14)$ & $7(14)$ & \\
$81-90$ & $1(2)$ & $0(0)$ & \\
Total & $50(100)$ & $50(100)$ & \\
Range & $21-90$ & $21-90$ & \\
Mean +SD & $60.80+12.37$ & $60.10+11.35$ \\
(years) & & & \\
\hline
\end{tabular}

Chi square test was done, which was not significant $(P>0.05)$

Out of 50 cases 31 (62\%) were male and 19(38\%) were female given a male to female ratio of 1.6:1. Among the 50 controls, $32(64 \%)$ were male and $18(36 \%)$ were female giving a male to female ratio of $1.7: 1$. Analysis revealed that no statistically significant difference was found between the sex distribution of the subjects of two groups $(P>0.05)$. This is shown in Table II

Tabel-II

Sex distribution of study subjects ( $n=100$, Control 50, case 50)

\begin{tabular}{lccr}
\hline Sex & \multicolumn{2}{c}{ Study Subjects } & p value \\
\cline { 2 - 3 } & Case & Control & \\
& No. $(\%)$ & No. $(\%)$ & \\
\hline Male & $31(62)$ & $32(64)$ & 0.836 \\
Female & $19(38)$ & $18(36)$ & \\
Total & $50(100)$ & $50(100)$ & \\
M:F & $1.6: 1$ & $1.7: 1$ & \\
\hline
\end{tabular}

Chi square test was done, which was not significant $(P>0.05)$

Observation shows $30(60 \%)$ subjects of case group and $34(68 \%)$ subjects of control group have the history of hypertension before ischemic stroke. Analysis revealed no statistically significant difference between the case group and control group regarding previous history of hypertension $(P>0.05)$. This is shown in Table III 
Table-III

Comparison of hypertension between case and control group ( $n=100$, Control 50, case 50)

\begin{tabular}{lcccc}
\hline Study Subjects & \multicolumn{3}{c}{ Hypertension } & p value \\
\cline { 2 - 4 } & Present No. (\%) & Absent No. (\%) & No. (\%) & \\
\hline Case & $32(60)$ & $20(40)$ & $50(100)$ & 0.405 \\
Control & $34(64)$ & $16(32)$ & $50(100)$ & \\
\hline
\end{tabular}

Chi square test was done, which was not significant $(P>0.05)$

The mean blood glucose level in case group was $11+2.58 \mathrm{mmol} / \mathrm{L}($ Mean $+\mathrm{SD}$ ) and that of control group was $5.8+0.72 \mathrm{mmol} / \mathrm{L}$ (Mean $+\mathrm{SD}$ ). Unpaired "t" test showed that there was significant difference of mean admission blood glucose level between the case and the control group $(\mathrm{P}<0.05)$. This is shown in Table IV.
In the case group $8(16 \%)$ subjects died in $1^{\text {st }}$ week in the case group and $1(2 \%)$ subject died in $1^{\text {st }}$ week in control group. Statistical analysis showed that there is significance in mortality during first week between the case and control group $(\mathrm{P}<0.05)$. This is shown in Table $\mathrm{V}$

Table-IV

Comparison of blood glucose between case and control group ( $n=100$, Control 50, case 50)

\begin{tabular}{|c|c|c|c|c|c|}
\hline \multirow[t]{2}{*}{ Admission RBS } & \multicolumn{2}{|c|}{$\begin{array}{l}\text { Case group } \\
\text { Range (8-20) }\end{array}$} & \multicolumn{2}{|c|}{$\begin{array}{c}\text { Control group } \\
\text { Range }(4.3-7.6)\end{array}$} & \multirow[t]{2}{*}{$P$ value } \\
\hline & Number & Mean +SD & Number & Mean +SD & \\
\hline $4-4.9$ & & $11+2.58$ & 6 & $5.8+0.72$ & 0.001 \\
\hline $5-5.9$ & & & 17 & & \\
\hline $6-6.9$ & & & 25 & & \\
\hline $7-8$ & & & 2 & & \\
\hline 8-8.9 & 11 & & & & \\
\hline $9-9.9$ & 10 & & & & \\
\hline $10-10.9$ & 7 & & & & \\
\hline $11-11.9$ & 10 & & & & \\
\hline $12-12.9$ & 4 & & & & \\
\hline $13-13.9$ & 2 & & & & \\
\hline $14-14.9$ & 3 & & & & \\
\hline $15-15.9$ & 1 & & & & \\
\hline $16-16.9$ & 0 & & & & \\
\hline $17-17.9$ & 0 & & & & \\
\hline $18-18.9$ & 0 & & & & \\
\hline $19-20$ & 2 & & & & \\
\hline Total & 50 & & 50 & & \\
\hline
\end{tabular}

Unpaired "t" test was done, which was significant $(P<0.01)$ 
In another observation 14 (28\%) subjects of case group and $6(12 \%)$ subjects of control groups died after 30 days of ischemic stroke. Statistical analysis showed that there is significant difference in mortality after 30 dayss between the case and control group $(\mathrm{P}<0.05)$. This is shown in Table VI

Table VII shows 21(58.33) subjects of case group and $16(36.36 \%)$ subjects of control group has become dependent after 30 days of ischemic stroke. On the other hand $15(41.67 \%)$ subjects in the case group and $28(63.64 \%)$ subjects in the control group become independent after 30 days of the event. Statistical analysis shows significant disability among case group after 30 days of the event $(P<0.05)$.

Table VIII shows that 8 (40\%) subjects who were treated for hyperglycemia became dependent whereas $13(81.25 \%)$ subject who were not treated for hyperglycemia became dependent. Statistical analysis shows significant difference between the treated and non treated group of admission hyperglycemia.

Table-V

Comparison of mortality in $1^{\text {st }}$ week between case and control group $(n=100)$

\begin{tabular}{lcccc}
\hline Study & \multicolumn{3}{c}{ Death in $1^{\text {st }}$ week } & p value \\
\cline { 2 - 4 } Subjects & Yes No. (\%) & No No. $(\%)$ & Total & \\
\hline Case & $8(16)$ & $42(84)$ & $50(100)$ & 0.036 \\
Control & $1(2)$ & $49(98)$ & $50(100)$ & \\
\hline Total & 9 & 91 & 100 & \\
\hline
\end{tabular}

Chi square test was done, which was significant $(P<0.05)$

Table-VI

Comparison of mortality in 30 days between case and control group $(n=100)$

\begin{tabular}{lcccc}
\hline Study & \multicolumn{3}{c}{ Death in 30 days } & p value \\
\cline { 2 - 4 } Subjects & Yes $(\%)$ & No $(\%)$ & Total & \\
\hline Case & $14(28)$ & $36(72)$ & 50 & 0.046 \\
Control & $6(12)$ & $44(88)$ & 50 & \\
\hline Total & 20 & 80 & 100 & \\
\hline
\end{tabular}

Chi square test was done, which was significant $(P<0.05)$

Table-VII

Comparison of disability among survivors after $1^{\text {st }}$ week and after 30 days in case and control group $(n=100)$

\begin{tabular}{lcccccc}
\hline Study & \multicolumn{5}{c}{ Death in 30 days } & p value \\
\cline { 2 - 6 } Subjects & $\begin{array}{c}\text { On } \\
\text { admission } \\
\text { No }(\%)\end{array}$ & $\begin{array}{c}\text { After } 1^{\text {st }} \\
\text { week No. } \\
(\%)\end{array}$ & \multicolumn{3}{c}{ After 30 days } & \\
\cline { 3 - 6 } & & & $\begin{array}{c}\text { Total } \\
\text { Disability }\end{array}$ & $\begin{array}{c}\text { Dependent } \\
\text { No. }(\%)\end{array}$ & $\begin{array}{c}\text { Independent No } \\
(\%)\end{array}$ & \\
\hline Case & $50(100)$ & $42(84 \%)$ & $36(72 \%)$ & $21(58.36)$ & $15(41.67)$ & 0.049 \\
Control & $50(100)$ & $44(98 \%)$ & $44(88 \%)$ & $16(36.66)$ & $28(63.64)$ & \\
\hline Total & 100 & 90 & 80 & 37 & 43 & \\
\hline
\end{tabular}

Chi square test was done, which was significant $(P<0.05)$ 
Table-VIII

Comparison of disability among survivors after 30 days between treated and non treated group of hyperglycemia ( $n=36$, treated 20 , non treated 16)

\begin{tabular}{lcccc}
\hline Study Subjects & \multicolumn{2}{c}{ Disability after 30 days } & Total & p value \\
\cline { 2 - 4 } & Dependent No. (\%) & Independent No. (\%) & No (\%) & \\
\hline Treated & $8(40)$ & $12(60)$ & $20(100)$ & 0.031 \\
Non treated & $13(81.25)$ & $3(18.75)$ & $16(100)$ & \\
\hline Total & 21 & 15 & 36 & \\
\hline
\end{tabular}

Chi square test was done, which was significant $(P<0.05)$

\section{Discussion:}

The present study was carried out to show the effect of admission hyperglycemia in patients with ischemic stroke irrespective of the cause of hyperglycemia. The study was done to find out the association of socio-demographic factors like age, sex, socioe-conomic status, personal habit like smoking, family history of stroke and other disease like hypertension as risk factor in the development of ischemic stroke. One hundred subjects with ischemic stroke were included in this study of which 50 subjects with ischemic stroke were in the case group with admission hyperglycemia (RBS > $8 \mathrm{mmol} / \mathrm{L}$ ) during admission and 50 subjects in control group were without hyperglycemia $(\mathrm{RBS}<8$ $\mathrm{mmol} / \mathrm{L}$ ) during admission. Regarding sex distribution, both the controls and cases were well matched with no significant statistical difference $(P>0.05)$. The study also showed that $26 \%$ of control group and $28 \%$ of case group had the family history of stroke. Statistical analysis found no significant difference between the two group regarding family history of stroke $(P>0.05)$. The study by Hayee MA et all ${ }^{8}$ also found positive family history in $26.06 \%$ of patients. In the present study, $60 \%$ of subjects in the case group and $68 \%$ of subjects in the control group were hypertensive. No statistically singnificant difference was noted between the two groups $(P>0.05)$.Previous study by Uddin $\mathrm{J}^{9}$ also found $60 \%$ of patients with ischemic stroke were hypertensive. Hyperglycemia is frequently seen in the acute phase of ischemic stroke affecting up to $20 \%$ to $50 \%$ of patients at presentation. In the present study, the mean admission blood glucose level was $11+2.58 \mathrm{mmol} /$ $\mathrm{L}$ (mean+SD) in the case group and $5.8+0.72 \mathrm{mmol} /$ $\mathrm{L}$ (mean+SD) in the control group with a cumulative mean value of $8.4+1.65 \mathrm{mmol} / \mathrm{L}$ (mean $+\mathrm{SD})$. Statistical analysis revealed significant difference between admission blood glucose level in the case and control group $(\mathrm{P}<0.05)$. In a previous study Nina $T^{10}$ showed mean blood glucose level at admission was $8.4 \pm 5.2 \mathrm{mmol} / \mathrm{L}$ (mean $\pm \mathrm{SD}$ ). This finding closely resembles the finding of the present study. Admission hyperglycemia was associated with higher mortality rate than was euglycemia. In this study, $16 \%$ patients of hyperglycemia group died in the first week in comparison with only $2 \%$ in the euglycemic group which is statistically significant $(P<0.05)$. Death in $1^{\text {st }}$ week was more in $61-70$ years age group $(6 \%)$ in the cases in comparison to $(2 \%)$ in the controls of the same age group. The result implies that admission hyperglycemia is an independent predictor of mortality in patients with ischemic stroke. The higher rate of death in the present study may be due to lack of early reperfusion and thrombolytic therapy and inadequate supportive treatment facilities in our hospital set-up.

Regarding mortality after 30 days of ischemic stroke, the hyperglycemic group showed mortality rate $28 \%$ in comparison with $12 \%$ in the euglycemic group. This indicates a 2.3 fold increase in mortality among the patients with admission hyperglycemia which is also statistically significant $(P<0.05)$. In this study, $58.33 \%$ survivors of the case group and 
$36.3 \%$ of the control group were severely disabled after 30 days of ischemic stroke. The remainder $41.67 \%$ of patients of the case group and $63.64 \%$ of the control group become functionally independent despite some residual disability $(P<0.05)$. Study done by Jose Alverez $S$ et al ${ }^{11}$ showed $51 \%$ become severely disabled and $49 \%$ become functionally independent at 3 months. The present study shows higher incidence of significant disability $(P<0.05)$ in the hyperglycemic group than the previous study.

\section{Conclusion:}

The study revealed that there is an association between on admission hyperglycemia and poor outcome after acute ischemic stroke. Admission hyperglycemia worsen the outcome and functional disability during the phase of ischemic stroke. The study also suggests that on admission glucose level is an important risk factor and should be immediately treated to reduce morbidity and mortality in acute ischemic stroke.

\section{Reference:}

1. World Health organization (WHO) task force recommendation on stroke prevention, diagnosis and therapy. Report of the WHO task force on stroke and other cerebro vascular disorders. Stroke, 1989; 20: 1407-31

2. Vancheri F, Curcio M, Burgio A, Salvaggio $S$, Gruttadauria G, Lunetta MC, Dovico R, Alletto $M$. Imparied glucose metabolism in patients with acute stroke and no previous diagnosis of diabetes mellitus. Q.J. Med 2005; 98 (2): 871-8
3. Islam N, Aftabuddin M, Moriwaki A. Blood glucose and ischemic brain damage: effect of hypoglycaemia on incomplete Ischemia induced brain damage. Bangladesh Journal of Neuroscience 1997; 9:8

4. Sieber FE, Smith DS, Traystman RJ. Wollman $\mathrm{H}$. Glucose : A re-evaluation of its intra operative use, anaesthesiology 1987; 67:72

5. Williams LS. Rotich J, Qi R, Fineberg N, Espay A. Bruno A, Fineberg SE, Tierney WR. Effect of admission hyperglycemia an mortality and costs in acute Ischemic stroke. Neurology 2002; 59: 67 -71

6. Lees KR, Walters MR, Acute Stroke and diabetes. Acute Stroke unit and cerebrovascular clinic. Western Infirmary Glasgow, UK 2005;1:9-14

7. http//www.medalreg.com/qhe/medal/ch37/3716/37-16-02-ver9.Php3

8. Hayee Ma, Ullah AKMA, Hoque A, Akther N. Analysis of risk factors in 472 cases, Bangladesh Journal of Neuroscience, 1998;14(2): 41-54

9. Uddin J, Association of lipid profile in Ischemic stroke (Thesis). Dhaka Medical College \& Hospital 2006.

10. Nina TG. Decrease mortality by normalizing blood glucose after acute ischemic stroke, Academic Emergency Medicine 2006;13: $174-80$

11. Jose Alvarez Sabin, Carlos AM, Impact of Admission hyperglycemia on stroke outcome after thrombolysis, Stroke 2004; 35:2493-99 